\title{
ANALYZING COMPUTER
}

\section{BASED PATIENT RECORDS:}

A REVIEW OF LITERATURE

TRICIA L. ERSTAD, MSN, RN

\section{A B $\mathbf{S} \mathbf{T} \mathbf{R}$ A $C \mathbf{T}$}

A wide-ranging literature review of computer-based patient record (CPR) implementation over the past decade reveals that clinical, workflow, administrative, and revenue enbancement benefits of the CPR outweigh barriers and challenges - but only if healthcare organizations redesign certain work processes. Among other key efforts, organizations must train and motivate users to navigate CPR systems, as well as develop a common structured language. Clinicians who used CPRs found that electronic access to clinical information saves time and provides a thorough and efficient way to manage patient information.

\section{K E Y W O R D S}

Computer-based patient record (CPR)

\section{Electronic medical record (EMR)}

Electronic patient record (EPR)

Clinical decision making

Workflow

CPR standards
Note: The terms Computer-based Patient Record (CPR), Electronic Medical Record (EMR), and Electronic Patient Record (EPR) are used synonymously in this discussion, and are used as they are referenced in each work.

In 1991, the IOM published a report recommending the implementation of the CPR by 2001 to improve the care of patients and to reduce waste. The Computer-based Patient Record Institute (CPRI) stated, if providers continue with their current paper systems, they will lack the tools needed to manage the quality and costs of healthcare, the scientific basis for healthcare will continue to be undermined, and healthcare reform will be impeded. Therefore, administrators and other people involved in allocating resources and selecting CPR systems need to be educated about the benefits and complexities of CPR systems. ${ }^{1}$

Ten years after the initial report, CPRs are still under review for cost justification. A survey by Lenhart, Honness, Covington, and Johnson ${ }^{2}$ found that only 55 of 329 family practice residency programs (17 percent) were currently using a CPR. Similarly, only 13 percent of HIMSS 2002 Leadership Survey ${ }^{3}$ respondents reported having a fully operational CPR system. Tang and Hammond ${ }^{4}$ stated that implementing an expansive, robust system is daunting, but the option of operating an integrated delivery system on paper is increasingly becoming a nonviable alternative.

\section{Definition of a CPR System}

The CPR is an integration of patient information systems that captures and stores demographic, financial, and medical information from ancillary services such as registration, billing, lab, radiology, pathology, pharmacy, and transcription. ${ }^{2,5-7}$ The CPR also includes the network that links these systems, databases, interfaces, physician order entry, electronic communication systems, and the clinical workstations. ${ }^{6}$ CPR systems are 
not simply automated forms of today's paper charts. Instead CPRs contain patient information, decision support, reference material, and payer information., ${ }^{2,5}$

To reap the full benefits of a CPR, organizations must redesign current workflows and practices to evolve into efficient providers of care. CPR systems are developed to meet the following goals: improve quality of care, reduce organizational expense, and produce a data stream for electronic billing., ${ }^{5-8}$ The CPR meets these goals through workflow automation, connectivity, and data mining. ${ }^{8}$

The CPRI's definition concurred with the other researchers, but added that the $\mathrm{CPR}$ provides protection of patient and provider confidentiality, has a defined vocabulary and standardized coding, produces documentation as a by-product of patient care, connects local and remote systems, and provides electronic support for secondary users (payers, policymakers, researchers).? Unfortunately, most CPR systems are unable to offer all of the components defined by the CPRI because "the technology is too complex and too expensive, doctors won't use computers, and standards don't exist." The problems associated with CPR definitions are discussed in the barriers and challenges section of this discussion.

\section{Benefits}

The advantages associated with implementing CPRs are well documented and are straightforward. The difficulty comes with placing a dollar figure to these advantages; consequently, few organizations have published studies describing the actual costs and benefits attained from implementing CPRs. ${ }^{10-11}$ The benefits associated with CPRs are organized into four categories: clinical, workflow, administrative, and revenue enhancement. Renner ${ }^{12}$ states that measuring all the benefits associated with CPRs is virtually impossible, and that it is probably safe to select those that can make the greatest financial difference, and incorporate them into a financial model.

Clinical benefits. Clinical benefits seen after implementing a CPR include: better access to the chart, improved clinical decision making and disease management, enhanced documentation, simplified patient education, and increased free time to spend with patients, accompanied by improved perception of care and quality of work life. These benefits ultimately result in better delivery of patient care., 9-10,13-15

First of all, implementing CPR systems improved access to the patient chart. CPRs gave staff access to the medical record, and eliminated the need for providers to locate and pull paper charts for patient information to answer questions or return telephone calls..$^{1,5,11,15-18}$ Electronic chart access was invaluable for telephone triage personnel and chart auditors, and eliminated problems associated with "the lost chart" because it was available from any workstation. ${ }^{11,19}$

${ }^{6 C}$ CPR improved clinical
decision making and disease
management through enbanced
integration of treatment
outcomes and reminders."

Second, CPRs improved clinical decision making and disease management through enhanced integration of treatment outcomes and reminders. Siwicki ${ }^{20}$ stated that physicians are required to retain an unmanageable amount of knowledge to deliver consistent care to patients.

Tierney, Overhage, and McDonald ${ }^{23}$ found that variations in treatment that cannot be explained by differences in patients have encouraged the wider use of practice guidelines in an attempt to reduce variation, increase healthcare quality, and lower the costs of care.

Khoury ${ }^{14}$ and Tierney et al ${ }^{23}$ suggested that the EMR might be the only practical way to apply practice guidelines while clinicians are delivering care to patients. Khoury ${ }^{14}$ cited three instances where computerized reminders resulted in improvements in quality of care, and found that a simple reminder generated at the moment of care resulted in physicians performing actions that would have otherwise been overlooked. To quantify these benefits, consider the 5 to 10 percent discount MedicaLogic and HealthMatics CPR clients saved in malpractice premiums, and the revenue generated for patients' health maintenance appointments because they utilized decision support reminders. ${ }^{21-22}$ Dollars are also saved with improved drug formulary compliance. ${ }^{15}$

Kaiser Permanente of Ohio saw these best practice guidelines compliance improvements after implementing a medical automated record system and adding reminders at the point of care: ${ }^{14}$

- Aspirin use in patients with coronary artery disease increased from 56 percent to 82 percent in 27 months, while lipid-lowering agents increased from 10 percent to 20 percent in 7 months.

- ACE inhibitor use in patients with congestive heart failure increased from 54 percent to 66 percent.

- Stratification (staging) for patients with diabetes mellitus and asthma increased to 76 percent in 26 months and 65 percent in 29 months respectively. In addition, referrals to podiatry for medium and high-risk diabetics increased from 14 percent to 66 percent in 12 months.

- Percentage of hypertensive patients taking non-recommended medications decreased from 16 percent to 12 percent in 12 months.

- Percentage of patients older than 64 years of age who were offered an influenza vaccination during a primary care visit increased from 56 percent to 69 percent in 36 months.

Mildon and Cohen ${ }^{19}$ and Tierney et $\mathrm{al}^{23}$ cited similar studies related to improved compliance with clinical guidelines.

Third, CPR tools ensured each note was complete, helped standardize chart quality, and minimized errors. Charts were legible and organized, visits were documented consistent to the level of service provided, and signing was more convenient when providers were able to view and sign from any workstation. ${ }^{17,19}$

Fourth, patient education was simplified because providers didn't need to 
worry about a copied supply of handouts. CPR products were used as tools for the providers to illustrate or explain procedures or conditions to patients, and handouts were printed directly from the system. ${ }^{19}$

Finally, CPRs increased free time, a result from improved workflow, and allowed physicians to spend more time with patients. ${ }^{1,12}$ CPR clients reported a greater quality of life for physicians and staff, while their patients reported an improved perception of the physician practice. $^{12,21}$

Workflow benefits. Workflow solutions save several people from doing the same work that others have already done, or save them from postponing their own tasks while others finish theirs. ${ }^{25}$ With a CPR, many people can make changes to the record from different locations in parallel. The data gathered at the initial encounter is carried over to each subsequent visit within the integrated delivery system, eliminating the need to re-gather information. Workflow benefits resulting from CPR implementation include improved data intake, reduced transcription costs, reduced labor costs, and improved communication and better management of referrals, lab results, prescriptions, and drug recalls.

The first workflow benefit was improved data intake. After implementing the CPR, patients were no longer frustrated by having to record the same information again and again on paper forms in different office settings. The CPR had all of that information readily available for providers. Dassenko and Slowinski ${ }^{5}$ reported a reduction in nurse intake time from 35 minutes to $20 \mathrm{~min}$ utes for initial office visits and from 35 minutes to 15 minutes for return visits at University of Wisconsin Hospital and Clinics. They attributed this greater efficiency to eliminating collection of redundant information, and enhancing documentation with assessment screens that display a patient's history, vital signs, weight, and medical problems.

Renner $^{12}$ cited a study from Duke University Medical Center where the time for one office visit was reduced by 13 percent for physicians and one minute for each pre-exam interview for the nurses. The time saving was found in documentation and was attributed to faster pre-encounter chart reviews and post-encounter recording of data in the chart. The physician's time with the patients stayed the same.

Second, when clinicians completed their documentation at the point of care, there was no need for transcription at the end of the day. Mildon and Cohen ${ }^{19}$ valued this as an estimated savings of $\$ 300$ to $\$ 1,000$ per month, per physician. For example, in a six-provider practice, transcription took 150 hours per week with a turnaround time of seven days before implementation of a CPR. After implementation of a CPR, transcription

\section{${ }^{66}$ hen clinicians completed} their documentation at the point of care, there was no need for transcription at the end of the day."

time decreased by one-third, turnaround time decreased to one day, and the practice was able to add two providers. However, it is not necessary to force all physicians to give up transcription to lower costs. In-house transcriptionists can use a CPR to increase transcription efficiency, spending more time transcribing and less time searching for, assembling, and reassembling charts. ${ }^{10,12,15,19}$

Third, CPRs reduce the need for clerical staff by reducing staff workload and improving work processes. Each user's workstation becomes a chart room, which gives staff access to the charts electronically instead of pulling and re-filing them manually. Basch ${ }^{26}$ reported adding several thousand more patients per year without additional staffing, eliminating overtime hours for medical assistants, and eliminating one full-time employee in medical records, while HITS (Healthcare
Innovations in Technology Systems) award winner Cooper Pediatrics quadrupled its practice base in five years. ${ }^{27}$ EMR clients found labor savings in patient chart handling, lab result handling, and copying expenses, while others cut medical record staff and changed duties from filing to electronic document scanning. ${ }^{10-12,17,21-22}$

Mildon and Cohen ${ }^{19}$ reported that one practice reduced its staffing to 2.2 FTEs per physician after implementing a CPR system. This is 2.11 FTEs below the Medical Group Management Association's calculated staffing ratio. Stammer ${ }^{28}$ cited that a chart pull costs $\$ 20$ at Scott and White Memorial Hospital, Clinic, and Health Systems in Temple, Texas. Their electronic chart solution reduced electronic chart pulls to less than $\$ 1$ apiece. In addition to savings in chart pulls, consider the costs associated with supporting paper-charting systems. When practices abandon paper, they abandon expenses that support paper such as filing systems and costs for paper supplies. ${ }^{10,16}$ Costs for a paper chart system are estimated at about three dollars per chart. ${ }^{10}$ In addition, practices can eventually reclaim the space used to store and file charts. ${ }^{11-12,15-16,19}$ CPRs also eliminated the labor and copying expenses associated with chart requests from outside of the healthcare delivery system. ${ }^{19}$

Fourth, CPRs have a built-in e-mail system, which results in improved communication by allowing staff the ability to message each other from any workstation. The CPR coordinated workflow communication in the business office and patient care departments. For example, the business office e-mailed the physicians when payers needed certification and justification for therapies, and physicians responded in a timelier manner. ${ }^{5}$

Finally, CPRs improve managing referrals, lab results, prescriptions, and drug recalls. ${ }^{12,17,24}$ Referrals that are submitted electronically extract the essential data from the CPR, eliminating the need for staff to manually summarize patient data to file with the referral. MedicaLogic clients reduced their turnaround time for referrals from one day to less than one hour. They also reduced their turnaround time for posting lab results from an aver- 
age 24-36 hours to less than 24 hours, and medication prescriptions and refills from 15 minutes to less than 3 minutes. Capital Region Healthcare, prescribing 400 prescriptions per week, saved $\$ 71,400$ per year on prescription tasks. ${ }^{24}$

Drug recalls are handled gracefully with a CPR. Providers simply query their database for all patients using the recalled drug and a report prints with the patients' demographics. Now patients can hear about drug recalls in a timely matter from their prescribing provider instead of from the media.

\section{Administrative benefits.}

Administrative benefits after CPR implementation include objective monitoring of physician practices, outcomes research, and disease management. CPR implementation also resulted in easier means to create report cards for managed care plans, simplified and improved claims processing, and better customer service. The structured data in the CPR enabled administrators to generate forms and graphs that show the data in an organized format.

CPR-structured databases enabled managers to monitor their providers' practice trends and compliance with screening recommendations such as mammograms and PSA levels. In addition to compliance with best practice guidelines, managers can track providers' favorite treatments or medications and compare outcomes for disease management. ${ }^{29}$ The managers can also assess a provider's "sick mix" and have objective data to provide bonuses for facility savings in managed practices. ${ }^{29} \mathrm{CPRs}$ also provide information to help organizations better understand how to position themselves in the market and plan for matters such as equipment acquisition. ${ }^{1}$

Data can be electronically captured in the CPR system and used for report cards like Health Plan Employer Data and Information Set (HEDIS) that are required by payers and regulators., 15 "Gathering the data to prepare these reports can be immensely time-consuming and costly when they are manually abstracted from paper records, but with a CPR, reporting on aggregate data can be a by-product of capturing data electronically"4 (p. 2)
Dassenko and Slowinski, ${ }^{5}$ Davis, ${ }^{11}$ Marietti, ${ }^{17}$ and Renner ${ }^{12}$ also found that claims processing was more efficient and complete with CPRs because of improved access to the chart and structured and encoded data. This resulted in quicker and less expensive bill production, and ultimately facilitated cash flow because bills were paid quicker when they were issued sooner. Timeliness in issuing bills also avoided penalties. Dassenko and Slowinski ${ }^{5}$ and MedicaLogic ${ }^{24}$ reported that in the past, substantial charges were written off because a bill was not submitted to a secondary payer on time. Before the CPR was implemented, a bill requiring information from an off-site folder might have waited two to three weeks for completion; in contrast, online information access allowed the bill to be in the mail within two or three days.

Another claims processing advantage cited by Dassenko and Slowinski ${ }^{5}$ and MedicaLogic ${ }^{24}$ was improved cash flow as a result of more complete billing. With the CPR, account representatives were able to view an organized chart and search the entire chart by a key word. From their workstations, patient accounting representatives accessed and printed such detailed information as physician notes and operative notes required by payers. Before the CPR, patient accounting representatives had to call each department for a photocopy of such information, and if too much time had elapsed, the patient accounting representative was instructed to submit the bill without the necessary information. If the payer denied the payment, the department that failed to provide the documentation was sent a copy of the denial, and asked to send the required document. ${ }^{5}$

Finally, Dassenko and Slowinski $i^{5}$ found that customer service was enhanced because patient accounting representatives were more available for questions and because questions were answered more completely and easily with online access to patient files. Most patient calls are very basic, and do not require the expertise of a patient accounting representative. If the information is organized and available online, other staff can han- dle these questions while patient accounting representatives can handle the more complicated problems.

Revenue enbancement. Mildon and Cohen ${ }^{19}$ stated, "There is more to money than saving it. CPRs also can enhance revenue." CPRs increase revenue through effective management of information at the point of care and in the billing office. Revenue enhancement depends on factors such as more effective health maintenance programs, better accuracy of coding, and improved administrative and workflow functions.

CPR systems enhanced revenue by increasing health maintenance visits. CPR systems provided tools and generated reminders based on patient age, gender, diagnosis, or procedures, and each time a chart was accessed, the CPR alerted the provider about overdue health maintenance issues. 19, 21 "In fee-for-service environments, health maintenance functions offer the potential of increasing the volume of services while ensuring better care for patients." ${ }^{19}$ Renner ${ }^{12}$ cited a study that found that the annual cost of all patient care was far lower for patients assigned to a CPR group (\$943) than those assigned to a paper chart group $(\$ 1,539)$. The researchers credited better preventive care and health maintenance given to the group whose records were kept electronically.

CPR systems also generated revenue through improved coding. According to industry estimates, the amount of money lost by inaccurate coding ranges from 3 percent to 15 percent of total practice revenue. ${ }^{19,24}$ Clinicians are conservative about coding due to the additional documentation burden and fear of an audit. CPRs assisted in recapturing this lost income by making it easier for providers to document visits and by helping them to code at the appropriate level. ${ }^{15,19,24}$ Medical Economics ${ }^{30}$ magazine estimated a $\$ 40,000$ to $\$ 50,000$ annual loss to physicians who routinely down-code one "E and M" (Evaluation and Management) level. CPRs helped with "E and M" coding and enabled providers to code correctly, with full supporting documentation. Mohr ${ }^{31}$ found that the use of dictation templates improved revenue capture 
by ensuring that documentation was adequate for associated charges.

Finally, many of the process improvements made with CPRs in administration and workflow discussed in the previous sections ultimately produce revenue enhancement. Benefits included improved claims processing, greater customer service that resulted in increased market share, and efficiencies that allowed practices to grow without increasing staff.

\section{Barriers and Challenges}

Despite all of these benefits, testimonies, and recommendations, CPRs are not a standard in today's healthcare systems. ${ }^{2-3}$ Even though the IOM's recommendation to implement CPRs is over 10 years old, it is evident that CPR technology is still a hot topic for discussion when browsing though current healthcare technology and management journals. The following barriers have kept healthcare leaders discussing CPR technology instead of adopting it: cost, leadership, ROI, vendors keeping up with users' needs, and deficits in the following categories: public policy, standards, security, and a true definition.

First of all, cost has kept organizations from implementing CPR systems. These costs can be organized into the following categories: software, hardware, infrastructure development and maintenance, implementation, education, planning, and administration. Software costs include development or purchase, maintenance, and upgrades over time, while hardware costs include purchase of workstations., 12, 24, 31 Infrastructure development and maintenance costs include servers, interfaces, workstations, network cables, network maintenance, and help desk operations. ${ }^{24,31}$ Planning costs include development of an implementation plan, identifying measurable outcomes, and choosing meaningful metrics and goals, while implementation costs include training, overtime associated with entering patient data, business disruption during transition, employee resistance to change, and lost productivity. 2, 12, 24, 31 Administrative costs include time and commitment to make the project succeed and ensuring that the $\mathrm{CPR}$ product meets credentialing requirements. ${ }^{12,24,31}$

When compared with other sectors of the economy, the healthcare industry is not committed to interactive information exchange..$^{15,34,36}$ Drazen $^{34}$ suggested that leadership was probably a more significant barrier than cost because, in the past, healthcare leaders have raised capital for essential business initiatives such as major building programs, acquiring a physician network, or starting up a managed care organization. This amount of capital is on the same scale as an EMR. The 13th Annual HIMSS Leadership Survey sponsored by Superior Consulting reported that CPR implementation came in seventh of eight top IT priorities for 2002. ${ }^{3}$

\section{${ }^{6} W$ ben compared with other sectors of the economy, the bealthcare industry is not committed to interactive information exchange."}

In addition, institutions have not been able to produce the ROI promised by vendors. ${ }^{9-10,15,24,36}$ Many factors that have been figured in vendors' ROI are dependent on difficult-to-change processes like point-of-care nursing documentation, physician order entry, and structured physician progress notes. ${ }^{8}$ For example, physician order entry is essential for decision support and medication management, and structured progress notes are necessary for transcription elimination and database building. ROI is difficult to calculate because each organization has its own business objectives and many of the benefits are qualitative rather than quantitative..$^{15}$ It is also difficult to establish the baseline costs of doing business manually to compare to the post-CPR implementation data.

Another challenge is that vendors have not kept up with organizations' needs for growth. Vicki Bosch, project leader of clinical informatics at MeritCare Health Center in Fargo, North Dakota, stated that, as users became more comfortable with the EPR, they started identifying ways to improve and refine the tools for clinical guidelines and health maintenance. Their primary EPR vendor didn't have solutions for these improvements, but a secondary vendor had put resources into refining the tools for an additional expense. Organizations that have implemented EPR systems and have contacts with specific vendors want to see product improvement without an increase in costs (personal communication, April 12, 2002).

Next, Drazen ${ }^{37}$ stated that a lack of government support is a major issue holding up CPR implementation. The recommendation in the IOM report was to establish the CPRI and to fund it as a public/private partnership. Unfortunately, the federal government did not contribute financially to CPR implementation projects. In addition, the federal government has never addressed the issue of CPR standardization. ${ }^{37}$ Without standards and structured data definitions, computer systems are not guaranteed to interface easily with each other, and databases are not easily developed. Most individual departments within a healthcare system have already invested in computerized patient information systems; however, these systems are isolated and do not communicate well with one another. Getting these systems to interface is one challenge facing EMRs. Because of this, McDonald ${ }^{38}$ suggested focusing on interfacing solutions in the form of standards (i.e., IP, HL7, ASTM, DICOM, LOINC, SNOMED) rather than EMR solutions to accelerate EMR deployment. The work required to interface with the many different island systems and regularize their data has been more than most can afford, ${ }^{38}$ and no individual CPR supplier, healthcare enterprise, or payer has the ability to create national standards at this time. ${ }^{37}$

Data security continues to be an ongoing challenge. Bergman ${ }^{32}$ found that politicians, consumer advocates, and the general public have voiced concerns about risks to the privacy and confidentiality of patient information. However, 
when compared with the security of the paper chart, the EMR's electronic audit trails and passwords actually improved internal security.

Dassenko and Slowinski ${ }^{5}$ stated that each EMR's subsystem contains a user profile defining the organization, user name, title, job function, and work area. This information is used to determine what information can be accessed and for what patient populations an individual is authorized. In addition, Dassenko and Slowinski ${ }^{5}$ reported that detailed records were created each time a user accesses certain categories of patient data, and that these access logs became part of a patient's permanent computerbased record, thus ensuring a reasonable level of confidentiality and discouraging inappropriate use. The security system not only creates access trails, but also documents patient chart movement and print requests. ${ }^{6}$

The EMR may be more secure for internal breeches of confidentiality, but must also be protected from external breeches such as hackers, who could potentially enter the EMR from an off-site location and download volumes of confidential information. Firewalls and encryption software are methods used to protect patient data from these violators. ${ }^{39}$

Finally, a universal definition of the CPR has not yet been developed..$^{4,8,32}$ Conflicting visions from CPR vendors, the clinical informatics community, the CPRI, the IOM, and the healthcare community have kept these individual groups from agreeing on an accepted definition and a mutual goal. As a result, Tang and Hammond ${ }^{4}$ stated that CPR implementation has been impeded because vendors do not know exactly what to supply and users have had a difficult time selecting a system that meets their needs.

Gaillour $^{8}$ suggested redefining the CPRI's vision by scaling down and aiming for a less perfect CPR, thereby increasing implementation rates. Then organizations could focus on implementing the easier components such as transcription, lab results, patient schedules, and ICD-9 capture. By eliminating difficult-to-implement features such as struc- tured data and decision support, organizations can aim for 100 percent provider participation, and will meet the multiple access goals for sharing information.

Drazen ${ }^{13}$ suggested focusing on supporting care processes that produce clear and valuable benefits rather than focusing on a theoretical ideal.

\section{Conclusion}

Clinicians who used CPRs recognized two axioms: First, electronic access to clinical information saves time. Second, electronic access provides a thorough and efficient way to manage patient information. With CPR systems, comprehensive information can be located and presented in a way that is relevant to the task at hand. ${ }^{5}$

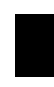

\section{${ }^{66} W$ hen compared with the} security of the paper chart, the
EMR's electronic audit trails and passwords actually improved internal security."

The obstacles identified in the barriers and challenges section have thus far been insurmountable, but the considerable achievements identified in the benefits section of this discussion suggest that the advantages are well worth the effort. As Lenhart et al state, "Success comes at the price of considerable effort, persistence, and optimism, as well as dedicated leadership."2 (p. 114) Some organizations that invested in early CPR systems are struggling to show the qualitative benefits promised by vendors because an electronic version of current work processes is not cost effective. ${ }^{9-10,15,24}$ "If the ROI were a function of the information tool itself, the financial benefits would be experienced universally." ${ }^{24}$ To get the most value out of a CPR, healthcare organizations must reengineer the following work processes to make full use of the system:
- Healthcare organizations must first train and motivate their users on how to navigate and operate the CPR tools. To optimally use the CPR it must be implemented from registration through billing, thus allowing the organization to realize full potential benefits across the delivery system. These benefits include clear, concise, and comprehensive documentation, greater efficiency, care consistent with best practice guidelines, and improved claims processing.

- When providers begin to function more efficiently, they will be able to spend more free time with their patients and increase their clientele. Spending more time with patients could improve customer satisfaction and boost market share, while seeing more patients could increase revenue.

- Organizations must come to an agreement on a structured language. This will enable the creation of patient databases, eliminate manual chart auditing, and improve coding. This improvement in data management will cut costs by enhancing efficiency, and more accurate coding will increase revenue.

- Finally, administrators must analyze the CPR and identify methods to reduce organizational waste. For example, malpractice carriers could be asked for reduction in premiums due to improved quality of care secondary to decision support tools. Administrators also must restructure jobs eliminated by the improved access and workflow benefits, and reduce or eliminate transcription services if encounter forms are working well.

It is difficult to measure the economic value associated with less tangible benefits such as higher quality of care, patient service, provider and employee satisfaction, and competitive advantage. It is even more difficult to allocate necessary resources and commit to institutional change when the paper chart is "getting the job done," even if it is not in the most efficient style.

However, Carlon ${ }^{40}$ suggests that all providers should embrace the EMR to deliver safe medical care. This is an important topic after the $\mathrm{IOM}^{41}$ released 
its widely debated report on medical errors in 2000. The information in the CPR can reduce medical errors to avoid dangerous, sometimes lethal, mistakes. If organizations can't show that CPRs have a positive ROI, they may decide that the $\mathrm{CPR}$ is just another expense of running a business. The expense is to improve patient safety and reduce medical errors and is rooted in the most basic and ancient obligation of the medical arts: First, do no harm. The CPR contributes to the ultimate goal of delivering effective care while improving patient safety.

\begin{abstract}
About the Author
Tricia L. Erstad, MSN, RN, is a registered nurse with a master's degree in nursing informatics.
\end{abstract}

\section{References}

${ }^{1}$ Institute of Medicine (IOM). The Computer-based Record: An Essential Technology for Healthcare, 2nd edition. Dick, R. S., Steen, E. B., Detmer, D. E., eds. Washington, DC: National Academy Press, 1997. Available at: http://stills.nap.edu/html/computer/. Accessed February 4, 2002.

${ }^{2}$ Lenhart, J. G., Honess, K., Covington, D., and Johnson, K. E. "An Analysis of Trends, Perceptions, and Use Patterns of Electronic Medical Records Among Family Practice Residency Programs." Family Medicine, February 2000, 32: 109-114.

${ }^{3} 13$ th Annual HIMSS Leadership Survey: Trends in Healthcare Information Technology. Healthcare Information and Management Systems Society (HIMSS) web site. Available at: http://www.himss.org/2002survey/ index.htm. Accessed October 1, 2002.

${ }^{4}$ Tang, P. C., and Hammond, W. E. "A Progress Report on Computer-Based Patient Records in the United States." In: Dick, R. S., Steen, E. B., Detmer, D. E., eds. The Computer-based Record: an Essential Technology for Healthcare. 2nd edition. Washington, DC: National Academy Press, 1997. Available at: http://stills.nap.edu/html/computer/ commentary.html. Accessed February 4, 2002.

${ }^{5}$ Dassenko, D., and Slowinski, T. "Using the CPR to Benefit a Business Office." Healthcare Financial Management, July 1995, 49: 68-70, 72-73.

${ }^{6}$ Kian. L., Stewart, M., Bagby, C., and Robertson, J. "Justifying the Cost of a Computer-based Patient Record." Healthcare Financial Management, July 1995, 49: 58-60, 62, 64, 66-67.

${ }^{7}$ CPRI Workgroup. Valuing CPR Systems: A Business Planning Methodology. Schaumburg, IL: Computer-based Patient Record Institute, 1997.

${ }^{8}$ Gaillour, F. "Rethinking the CPR: Is Perfect the Enemy of the Good?" Healthcare Management Technology [serial online], May 1999, 20: 22-25.

${ }^{9}$ Fromberg, R., and Amatayakul, M. "CPRI and the Future of Computer-based Patient Records." Healthcare Financial Management, July 1995, 49: 48, $50,52,54,56-57$.

${ }^{10}$ Bingham, A. "Computerized Patient Records Benefit Physician Offices." Healthcare Financial Management, September 1997, 51: 68-70.

${ }^{11}$ Davis, M. W. "Reaping the Benefits of Electronic Medical Record Systems." Healthcare Financial Management, June 1993, 46: 60-62, 64, 66.

${ }^{12}$ Renner, K. "Electronic Medical Records in the Outpatient Setting." Medical Group Management Journal, May/June 1996, 43: 52, 54, 56-57, 74.

${ }^{13}$ Drazen, E. "Is This the Year of the Computer-based Patient Record?" Healthcare Informatics, February 2001, 18: 94, 96, 98.

${ }^{14}$ Khoury, A. "Support of Quality and Business Goals by an Ambulatory Automated Medical Record System in Kaiser Permanente of Ohio." Effective Clinical Practice, October/November 1998, 1: 73-82.

${ }^{15}$ Sandrick, K. "Calculating ROI for CPRs." Healthcare Management Technology [serial online], May 1998. Available at: http://www.healthmgttech.com/ . Accessed April 16, 2002.

${ }^{16} \mathrm{HaO}, \mathrm{M}$. "What Works. Hospital Cuts Records Staff and Rent with Electronic Patient Charting." Health Management Technology [serial online], October 1997, 18: 38.

${ }^{7}$ Marietti, C. "Case in Point: Children's Hospital in Boston. From the Emergency Department to the World." Healthcare Informatics, May 1998, 15: 94-95.

18"MeritCare Health System - Providing Exceptional Patient Care." In: Electronic Medical Record: Value Analysis. Irving, TX: VHA, Inc., 1998.

${ }^{19}$ Mildon, J., and Cohen, T. "Drivers in the Electronics Medical Records Market." Health Management Technology, May 2001, 22: 14-6, 18.

${ }^{20}$ Siwicki, B. "Outpatient Electronic Records. Tackling the Challenges." Health Data Management, May 1997, 5: 66-68, 70, 74, 76-78, 81.

${ }^{21}$ HealthMatics Electronic Medical Record System. Available at: http://www.a4healthsys.com/ROi.pdf . Accessed January 12, 2002.
${ }^{22}$ MedicaLogic. Ambulatory EMR: Establishing a Business Case. Available at: http://www.medicalogic.com/download/www/emr/whitepapers/ business_case.pdf. Accessed January 15, 2002.

${ }^{23}$ Tierney, W. M., Overhage, J. M., and McDonald, C. J. "Demonstrating the Effects of an IAIMS on Health Care Quality and Cost." Journal of the American Medical Informatics Association, March/April 1997, 4(suppl): S41-S46.

${ }^{24}$ ROI: The White Paper. A Business Case for Electronic Medical Records. Beaverton, OR: Medicalogic pamphlet.

${ }^{25}$ Essex, D. "The Many Layers of Workflow Automation." Healthcare Informatics, June 2000, 17: 121-122, 124-130.

${ }^{26}$ Basch, P. "Electronic Medical Records: A Worthwhile Return on Investment. Washington Primary Care Physicians Use of Logician - Year One Analysis." In: Electronic Medical Record: Value Analysis. Irving, TX: VHA, Inc., 1998.

${ }^{27}$ May, S. "A CPR System Can Grow a Practice." Healthcare Informatics [serial online], January 2002. Available at: http://www.healthcare-informatics.com/ issues/2002/01_02/HITS.htm. Accessed February 2, 2002.

${ }^{28}$ Stammer, L. "Chart Pulling Brought to Its Knees." Healthcare Informatics [serial online], February 2001, 18: 107-108.

${ }^{29}$ Willey, C. J., and Struckhoff, B. "Physicians Use EMR to Improve Quality." Medical Group Management Journal, November/December 1999, 46: 18-21, 24-27.

${ }^{30}$ Medical Economics, August 24, 1998.

${ }^{31}$ Mohr, D. "Benefits of an Electronic Clinical Information System." Healthcare Information Management, Winter 1997, 11: 49-57.

${ }^{32}$ Bergman, R. "Where There's a Will...Computer-based Patient Records Require Commitment, Time - and Money." Hospitals and Health Networks, May 5, 1994, 68: 36, 38, 40, 42.

${ }^{33}$ Detmer, D. E., and Steen, E. B. Preface. In: Dick, R. S., Steen, E. B., Detmer, D. E., eds. The Computer-based Record: an Essential Technology for Healthcare. 2nd edition. Washington, DC: National Academy Press, $1997, \mathrm{v}-\mathrm{x}$.

${ }^{34}$ Drazen, E. "Why Don't We Have Computer-based Patient Records?" Journal of American Health Information Management Association, June 1996, 67: 56-60.

${ }^{35}$ Sandrick, K. "CPRs: Why Some of the Best Work So Well." Healthcare Management Technology [serial online], October 1997, 19: 16-20.

${ }^{36}$ Waegemann, C. P. "Leading Edge: An Electronic Health Record for the Real World." Healthcare Informatics [serial online], May 2001. Available at: http://www.healthcare-informatics.com/issues/2001/05_01/ waegemann.htm. Accessed March 21, 2002.

${ }^{37}$ Drazen, E. "Point Counter-point: Computer-based Patient Record. Interview by C. Marietti." Healthcare Informatics, May 1998, 15: 84-86, 88-90, 94-96.

${ }^{38} \mathrm{McD}$ Donald, C. J. "The Barriers to Electronic Medical Record Systems and How to Overcome Them." The Journal of the American Medical Informatics Association, May 1997, 4: 213-221.

${ }^{30}$ Kendall, K. E., and Kendall, J. E. Systems Analysis and Design. 4th ed. Upper Saddle River, NJ: Prentice Hall, 1999.

${ }^{40}$ Carlon, G. C. The Electronic Medical Record and the Oath of Hippocrates. How the EMR Helps 'Do No Harm." Health Management Technology [serial online], May 2000, 21: 16.

${ }^{41}$ Institute of Medicine (IOM). To Err is Human: Building a Safer Health System. Kohn, L. T., Corrigan, J. M., and Donaldson, M. S., eds. Washington, DC: National Academy Press, 2000. Available at: http://books.nap.edu/books/0309068371/html/index.html. Accessed April 22, 2002. 